\title{
Metabolism and Functions of Inositol \\ Pyrophosphates: Insights Gained from the Application of Synthetic Analogues
}

\author{
Stephen B. Shears * and Huanchen Wang \\ Inositol Signaling Group, Signal Transduction Laboratory, National Institute of Environmental Health Sciences, \\ National Institutes of Health, Research Triangle Park, NC 27709, USA; huanchen.wang@nih.gov \\ * Correspondence: shears@niehs.nih.gov; Tel.: +1-984-287-3483
}

Academic Editors: Marie Migaud and Gerd Wagner

Received: 30 August 2020; Accepted: 27 September 2020; Published: 2 October 2020

check for updates

\begin{abstract}
Inositol pyrophosphates (PP-InsPs) comprise an important group of intracellular, diffusible cellular signals that a wide range of biological processes throughout the yeast, plant, and animal kingdoms. It has been difficult to gain a molecular-level mechanistic understanding of the actions of these molecules, due to their highly phosphorylated nature, their low levels, and their rapid metabolic turnover. More recently, these obstacles to success are being surmounted by the chemical synthesis of a number of insightful PP-InsP analogs. This review will describe these analogs and will indicate the important chemical and biological information gained by using them.
\end{abstract}

Keywords: metabolism; homeostasis; phosphate; cell biology; energy

\section{Introduction}

The inositol pyrophosphates (PP-InsPs), particularly 1-InsP 7 , 5-InsP $\mathrm{P}_{7}$, and 1,5-InsP 8 (Appendix A; Figure 1) are highly 'energetic' and diffusible signaling molecules that play important roles in many cellular processes throughout the eukaryotic kingdoms, particularly with regards to phosphate and bioenergetic homeostasis, both of which can have profound metabolic and physiological consequences [1-8]. Indeed, it is hard to overstate the significance of dovetailing any signal transduction cascade with metabolic circuitry. All biological programs place bioenergetic demands upon an organism; its ability to adapt to environmental challenges, i.e., its long-term survival, is reliant upon signaling cascades exerting dynamic control over the uptake, storage, and utilization of various metabolic fuels [9]. Our understanding of the many roles that PP-InsPs play in these processes has been especially well-served in recent years by the contributions that organic chemists have made in synthesizing insightful PP-InsP analogs. Here, we review the nature of these tools and the knowledge gained from their use. 


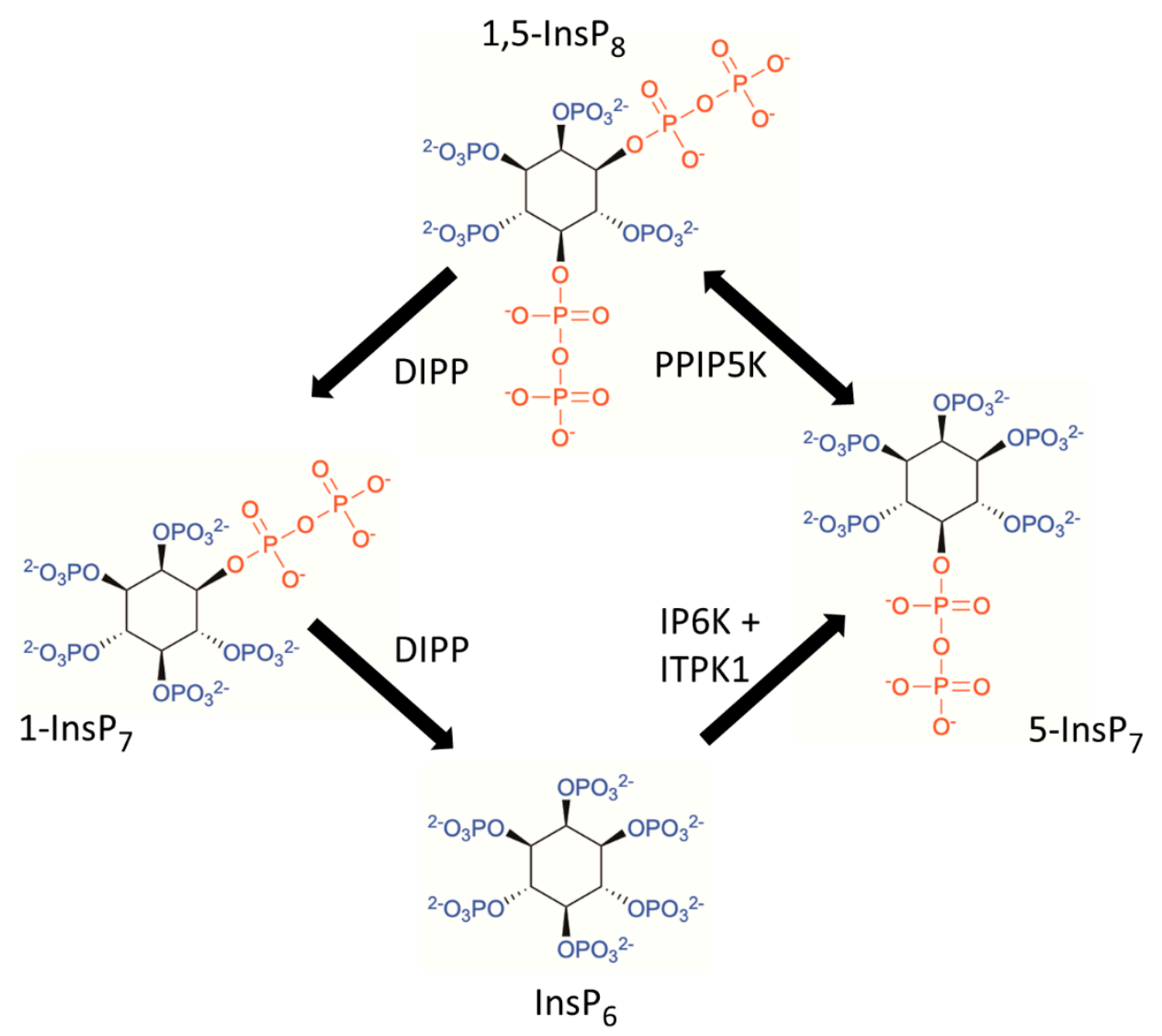

Figure 1. The inositol pyrophosphate (PP-InsP) metabolic pathway. This graphic incorporates a proposal $[1,2]$ that the pathway for $1,5-\mathrm{InsP}_{8}$ turnover principally comprises a cyclical interconversion of InsP $_{6}, 5$-InsP $7,1,5-$ InsP $_{8}$, and 1-InsP $P_{7}$. ITPK1 = inositol 3,4,5,6-tetrakisphosphate 1-kinase; IP6K = inositol hexakisphosphate 5-kinase; PPIP5K = diphosphoinositol pentakisphosphate 1-kinase (in addition to hosting a self-contained kinase domain, this class of enzyme also contains a phosphatase domain that possesses 1,5-InsP $\mathrm{P}_{8}$ 1-phosphatase activity [2-4]); DIPP = diphosphoinositol polyphosphate phosphatase.

\section{PP-InsP Synthesis and Metabolism}

Considerable attention has been given to two classes of kinases that work together to generate PP-InsPs (Figure 1): IP6Ks (see [6]), which until very recently were considered solely responsible for phosphorylating $\mathrm{InsP}_{6}$ to 5 -InsP $\mathrm{P}_{7}$, and the PPIP5Ks (see [2]), which interconvert 5-InsP $\mathrm{P}_{7}$ with 1,5-InsP $\mathrm{P}_{8}$. However, it has been enigmatic that orthologs of IP6Ks are not expressed in plants. This conundrum was recently resolved with the determination that the 'missing' Ins $_{6}$ kinase activity in plants is expressed by ITPK1s [10-12], a class of enzyme that had been originally characterized as active Ins $(3,4,5,6) \mathrm{P}_{4} 1$-kinases [13]. Human ITPK1 also expresses this $\operatorname{InsP}_{6}$ kinase activity in vitro [10], but it has yet to be demonstrated if it is sufficient in vivo to be considered a genuine, alternate source of 5-InsP $\mathrm{P}_{7}$ synthesis. Incidentally, an ITPK1 ortholog has not been identified in any yeast or insect genome.

The major pathway for net catabolism of 1,5-InsP 8 back to $\operatorname{InsP}_{6}$ in animal cells (see Figure 1) is proposed to occur by successive 5 - $\beta$-phosphatase and then 1- $\beta$-phosphatase activities of the diphosphoinositol polyphosphate phosphatases (DIPPs), although the 1-InsP $\mathrm{P}_{7}$ (Figure 1) is only a short-lived intermediate [1,14]. In Saccharomyces cerevisiae, this pathway of $1,5-\mathrm{InsP}_{8}$ turnover is reinforced through its hydrolysis by an additional 5-phosphatase activity catalyzed by Siw14 [15,16]. No animal orthologs of Siw14 have been identified to date. 


\section{Metabolically Stable Analogues of 5-InsP 7}

A number of studies have explored the biological activities of the PP-InsPs by pharmacological and/or genetic intervention in the metabolic pathway described by Figure 1 (see $[6,8]$ for recent, authoritative reviews). However, the blockage of IP6K activity by itself cannot distinguish the actions of 5-Ins $\mathrm{P}_{7}$ from those of InsP $\mathrm{P}_{8}$, since the synthesis of both is reduced. The inhibition of PPIP5K activity is not a specific strategy either; both $\mathrm{InsP}_{8}$ and $1-\mathrm{InsP}_{7}$ synthesis is compromised, and there is a significant elevation in 5-InsP $\mathrm{P}_{7}$ levels [17-19]. Thus, genetic and pharmacological experiments do not necessarily attribute a particular phenotype to the action (or loss of action) of one specific PP-InsP isomer. This is a situation in which metabolically stable PP-InsP analogs can be helpful, particularly with regards to biochemical and cellular assays, in which the natural PP-InsPs have a short half-life due to their inherently fast turnover rate $[20,21]$. Another application for such research tools is to distinguish between the two molecular mechanisms by which protein function can be modulated by the PP-InsPs: allosteric regulation upon ligand binding, versus covalent regulation by non-enzymic phosphotransfer $[1,6-8,22]$. The latter cannot be mimicked by metabolically stable PP-InsP analogs.

Two teams of researchers have separately pioneered the development of metabolically stable PP-InsP molecules: Barry Potter's UK group and Dorothea Fiedler's laboratory, which is now based in Germany. These reagents (Figure 2; Appendix A) were first described in 2012-2013 [23,24]. Fiedler and colleagues synthesized methylene-bisphosphonate (PCP) analogs of 5-InsP $\mathrm{P}_{7}$ in which a methylene group was substituted for the bridging oxygen of the phosphoanhydride moiety (Figure 2A and [24]). Potter's group replaced the bisphosphate of $5-\mathrm{InsP}_{7}$ with phosphonoacetate (PA) [23]. Subsequently, the PA- analog of 1,5-InsP 8 and PCP-analogues of $1-$ InsP $_{7}$ and 1,5-InsP 8 were also synthesized [25-27].

A

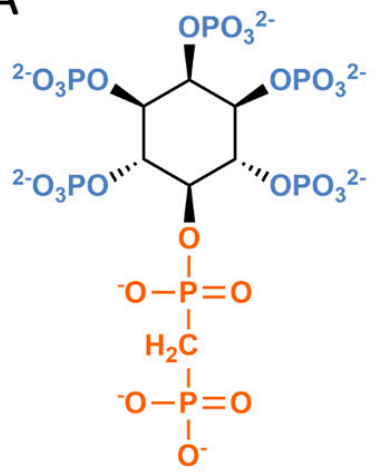

B

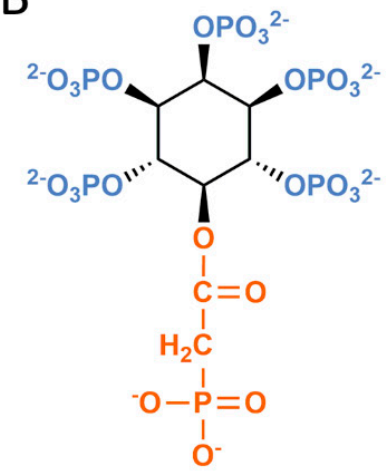

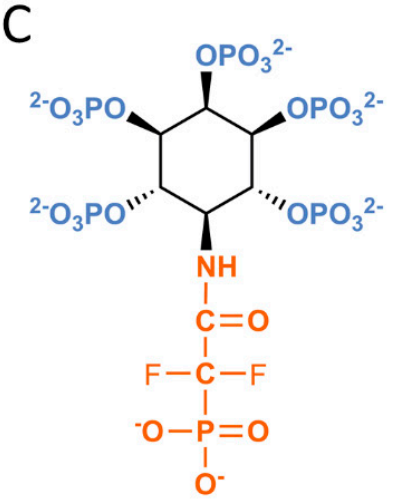

Figure 2. Metabolically stable bioisosteres of 5-Ins $\mathrm{P}_{7}$. This figure shows synthetic analogs of 5-InsP in which the phosphoanhydride group is replaced with either (A) methylene-bisphosphonate (PCP), (B) phosphonoacetate (PA), (C) phosphonodifluoroacetamide.

The authors of the latter studies have referenced earlier work [28] that notes the replacement of an oxygen atom with a methylene group leads to a reduction in the acidity of the phosphonic acid when compared to the phosphoric acid. The pKa values for the second deprotonations are such that the phosphonate will be less strongly ionized at physiological $\mathrm{pH}$ compared to the phosphate, potentially leading to a decreased affinity for protein receptors [28]. Despite this caveat, several significant discoveries have emerged from the application of these analogs, and these advances are described in the Sections below.

Potter group's recently synthesized a new analog in which the phosphonate $\mathrm{CH}_{2}$ group was replaced by a more electronegative $\mathrm{CF}_{2}$, thereby increasing the acidity of the moiety (Figure $2 \mathrm{C}$ ) and potentially narrowing the difference in $\mathrm{pKa}$ values compared to the natural diphosphate [28]. Since a difluoroacetate ester would be very labile to hydrolysis, a stable amide linkage was used (Figure 2C and [29]). 


\section{Bioisosteres and the Discovery of a PP-InsP Capture Site in the Kinase Domain of PPIP5K}

To enforce the tight substrate specificity of the PPIP5Ks for 5-InsP $\mathrm{P}_{7}$ and, to a minor extent InsP $_{6}$, ligand entry into the catalytic pocket is guarded by substantial architectural and electrostatic constraints [30]. This situation suggests ligand is only admitted when it is presented in the appropriate orientation, i.e., a direct hit. Could that limit the enzyme's ability to attract ligand that rotates and diffuses randomly through the bulk phase? For an illustrative analogy, consider the frustratingly customary outcome of a classic carnival game: the high failure rate when attempting to throw a table tennis ball into the narrow neck of a distant goldfish bowl.

Our X-ray analysis of 5-PA-InsP 7 soaked into crystals of the kinase domain of PPIP5K (i.e., PPIP5K ${ }^{K D}$ ) helped to uncover a near-unique mechanism by which this enzyme activity facilitates substrate access to the active site: two ligand-binding positions were observed [31]. Both ligand-binding sites cannot be occupied by substrate simultaneously, due to steric clashing. Thus, we reasoned that the crystal complexes comprised a mixture of two separate, but mutually exclusive ligand configurations. One of the binding sites for 5-PA-InsP $\mathrm{P}_{7}$ is near superimposable upon that occupied by 5 -Ins $\mathrm{P}_{7}$ in the catalytic pocket (Figure $3 \mathrm{~A}$ ). A second binding site lies approximately $8 \AA$ away, closer to the surface of the protein (Figure 3B). We propose the latter enhances substrate capture from the bulk phase, prior to its delivery into the catalytic pocket. We have described this phenomenon as a "catch-and-pass" reaction mechanism [31]. In an earlier study, we could not detect 5-InsP $\mathrm{P}_{7}$ substrate in the capture site [30]. Perhaps a slight difference in the degree of the positive charge of 5 -Ins $\mathrm{P}_{7}$ vis-a-vis its synthetic analog is responsible for the different behavior. We presume that the delivery of natural substrate is more efficient compared to 5-PA-InsP ${ }_{7}$, and hence the natural ligand occupies the capture site too transiently to yield suitable electron density.

A

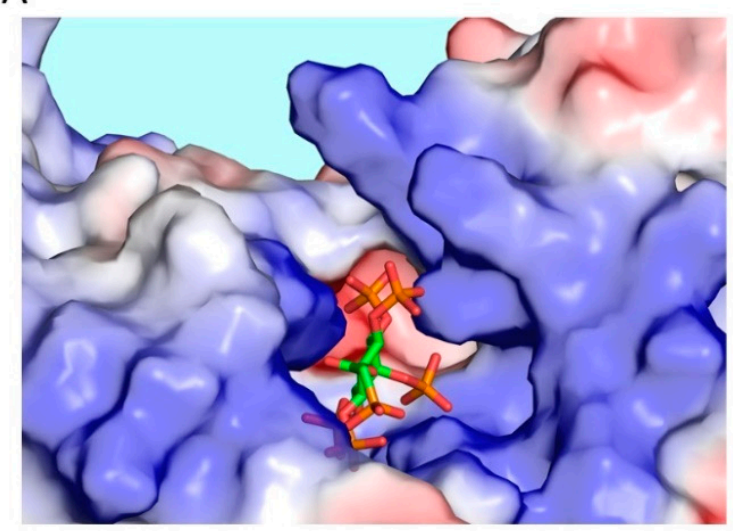

B

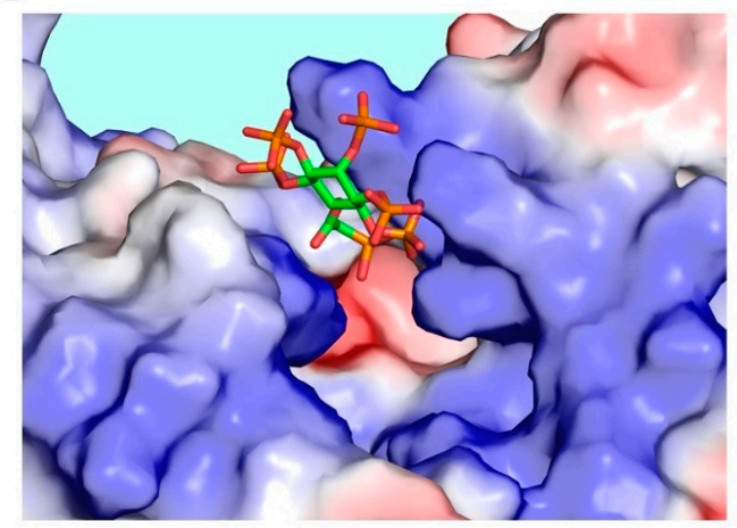

Figure 3. PPIP5K $\mathrm{K}^{\mathrm{KD}}$ has two substrate binding sites. X-ray crystallographic analysis of PPIP5K $\mathrm{K}^{\mathrm{KD}} / 5-\mathrm{PA}-\mathrm{InsP}_{7}$ crystal complexes uncovered two mutually exclusive ligand binding sites: (A) catalytic pocket; (B) substrate capture site. The protein is depicted in surface plot format, in which the intensity of the coloration (blue = positive, red = negative) corresponds to the degree of electrostatic polarization. The ligand is shown in stick form: carbon is green, phosphorous is orange, and oxygen is red.

The $8 \AA$ journey that 5 -InsP 7 takes when moving between its two binding sites has been modeled by the application of molecular dynamics simulations [32]. This was how we established the role of Glu192 as a molecular ratchet that moves towards the space vacated by the substrate. That is, the Glu192 electrostatically enforces one-way substrate delivery [32]. The concept that this residue is catalytically important has been verified experimentally-a Glu192Gln mutation dramatically reduces kinase activity, presumably by compromising substrate transfer into the active site [31].

The new phosphonodifluoroacetamide analog (Figure 2C) has also been soaked into crystals of

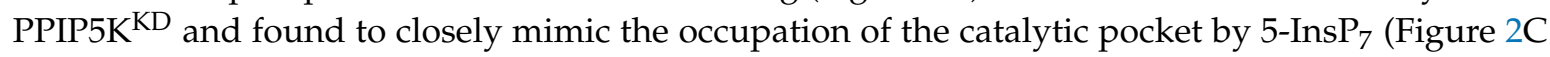


and [29]); the capture site was not occupied. Interestingly, there is a $\mathrm{Mg}^{2+}$ ion that makes contact with $5-\mathrm{InsP}_{7}$ in its crystal complex with PPIP5K ${ }^{\mathrm{KD}}$, but the metal is missing from the complex with the phosphonodifluoroacetamide analog. Therefore, it was suggested that this new analog might be particularly useful for studying those PP-InsP/protein interactions that are $\mathrm{Mg}^{2+}$-independent [29]. As it happens, there may be many such interactions: it has been noted by others that, to date, $\mathrm{Mg}^{2+}$ is missing from all of the published non-catalytic protein/PP-InsP complexes that have been captured by $\mathrm{x}$-ray crystallographic analyses [33].

The analysis of a crystal complex of PPIP5K $\mathrm{KD}^{\mathrm{KD}} 1,5-\mathrm{PA}-\mathrm{InsP}_{8}$ showed that this particular analog of the PPIP5K enzymatic product also occupies both ligand binding sites [25]. This observation raises the possibility that the product escapes from the catalytic pocket via the same capture site. In contrast, in corresponding crystal complexes that contain either 1,5-PCP-InsP $\mathrm{P}_{8}$ or $5-\mathrm{PCP}-\mathrm{InsP}_{7}$, these ligands were only observed in the catalytic pocket $[25,27]$, just as is the case with the natural substrates [30,34]. Nevertheless, the PA-version was more informative because it identified the capture site. This comparison underscores the scientific value of probing biological systems with a variety of different analogs.

\section{The Positional Specificity of DIPPs: Information Gained from PCP-InsPs}

The DIPPs show a high rate of hydrolytic activity towards all PP-InsPs [14], but there is a puzzling aspect to the enzymes' positional specificity. Biochemical assays have indicated that the 5 - $\beta$-phosphate is preferentially cleaved from $1,5-\mathrm{Ins}_{7}$ [14]. Despite that, these enzymes show a greater preference for the 1- $\beta$-phosphate of $1-\mathrm{InsP}_{7}$ compared to the $5-\beta$-phosphate of $5-\mathrm{InsP}_{7}[14,35]$. Moreover, PCP analogs have been useful in validating the enzyme's preference for $1-\mathrm{InsP}_{7}$ over 5 -InsP $\mathrm{P}_{7}$. PCP analogs are not hydrolyzed by DIPPs, but by competing with the active site, they act as inhibitors of PP-InsP hydrolysis $[25,26,35]$. Fiedler and colleagues showed that $1-\mathrm{PCP}-\mathrm{InsP}_{7}$ is an 80 -fold more potent inhibitor of DIPP activity than is 5-PCP-Ins $\mathrm{P}_{7}$ [26]. Such data are consistent with the aforementioned observation that DIPP prefers to hydrolyze $1-\mathrm{InsP}_{7}$ over $5-\mathrm{InsP}_{7}$. It is noteworthy that these biochemical assays were performed in media containing the $\mathrm{Mg}^{2+}$ that is necessary for activity. In contrast, $\mathrm{Mg}^{2+}$ was absent when Potter and colleagues [35] assessed apparent ligand affinities for DIPP by using differential scanning fluorimetry. Under such conditions, the apparent $\mathrm{K}_{\mathrm{d}}$ values for 1-Ins $\mathrm{P}_{7}$ and 5-InsP $\mathrm{P}_{7}$ are very similar, while the apparent $\mathrm{K}_{\mathrm{d}}$ value for 5 -PCP-InsP $\mathrm{P}_{7}$ is 3 to 4 -fold lower than that for 1-PCP-Ins $\mathrm{P}_{7}$ [35]. The fact that PCP versions of PP-InsPs recapitulate this $\mathrm{Mg}^{2+}$-dependence for DIPP's preferential apparent affinity for $1-\mathrm{InsP}_{7}$ over $5-\mathrm{InsP}_{7}$ is testimony to their value as bioisosteres.

\section{Application of Metabolically-Stable PP-InsP Analogues in Studies of Protein Pyrophosphorylation}

By definition, metabolically-stable analogs of PP-InsPs cannot participate in phosphoryl transfer reactions; in fact, the PCP-analogues inhibit protein pyrophosphorylation, which presumably reflects their competitively inhibiting the natural PP-InsP from binding to the protein [26]. Such a phenomenon speaks to the pyrophosphorylation event requiring a specific binding event that could enforce PP-InsP specificity [26]. That is another valuable conclusion to be drawn from the use of these analogs.

Metabolically-stabilized derivatives of PP-InsPs (like PP-InsPs themselves) cannot penetrate into intact cells. Thus, to date, the use of these analogs to probe the possibility of protein pyrophosphorylation has been restricted to cell-free, in vitro assays. For example, there has been an investigation into the roles of PP-InsPs in regulating phosphorylation of interferon regulatory factor 3 (IRF3) [36]. This is a key step in inducing cellular interferon- $\beta 1$ expression in response to viral infection. It was found that IRF3 phosphorylation in vitro is stimulated by 1-Ins $\mathrm{P}_{7}$ and/or $\mathrm{InsP}_{8}$ [36]. Since the corresponding PA-analogues of 1-Ins $\mathrm{P}_{7}$ and $\mathrm{InsP}_{8}$ proved to be inactive in this assay, it was concluded that the underlying mechanism for IRF3 activation likely involved protein pyrophosphorylation.

Another example has been a study of PP-InsP-mediated regulation of vesicle trafficking driven by cytoplasmic dynein 1 [37]. The latter is an important microtubule-based motor in many eukaryotic 
cells. In vitro, the dynein intermediate chain (IC), a non-catalytic dynein subunit, was shown to be pyrophosphorylated by 5 -Ins $\mathrm{P}_{7}$ on its $\mathrm{N}$-terminus, which in turn promotes dynein-IC binding to the p150Glued subunit of dynactin [37]. Notably, 5-PCP-InsP $\mathrm{P}_{7}$ was considerably less effective at enabling these protein-protein interactions [37], consistent with the idea that protein pyrophosphorylation is required.

\section{Protein Stability}

Potter and colleagues have used differential scanning calorimetry to show that the binding to DIPPs of either 1-PCP-Ins $\mathrm{P}_{7}$ or 5-PCP-InsP $\mathrm{P}_{7}$ elevates the protein's thermal transitions temperature-which reflects increased protein stability - to almost the same degree as the corresponding PP-InsPs [35]. The authors posited that any protein stabilization by metabolically-stable PCP-InsPs might facilitate the formation of tractable crystal/ligand complexes for X-ray structural analysis.

\section{Interrogation of the $5-\operatorname{Ins} P_{7}$ Interactomes}

Fiedler's group has prepared affinity resins to which 5-PCP-Ins $\mathrm{P}_{7}$ has been immobilized by attachment of a linker to the 2-phosphate. This metabolically-resistant ligand has been deployed to search for 5-InsP $\mathrm{P}_{7}$ binding partners in lysates of $S$. cerevisiae [38]. This particular application for the PCP-analogue yielded several interesting conclusions. Firstly, gene ontology analysis of the 'hits' showed a significant over-representation of proteins with bioenergetically important roles, such as nucleotide metabolism, glucose metabolism, and the energetically-intensive process of ribosome biogenesis. The nature of this cohort dovetails with the overarching concept that PP-InsPs play multiple roles at the interface of signaling and metabolic homeostasis [1].

This work was also informative because of the two separate screening conditions that were used: One contained $1 \mathrm{mM}$ exogenous $\mathrm{Mg}^{2+}$, and in a second screening, endogenous $\mathrm{Mg}^{2+}$ was chelated by the addition of EDTA [38]. Similar numbers of proteins were identified in each screen (98 and 84 , respectively), but only 21 overlapped both datasets. This is a singular observation that speaks to the existence of two structurally- and operationally-distinct PP-InsP binding sites. The authors speculated that $\mathrm{Mg}^{2+}$-independent binding could largely depend upon basic, positively charged amino-acid residues, whereas $\mathrm{Mg}^{2+}$-dependence may reflect the previously-demonstrated absolute dependence upon the cation for non-enzymic pyrophosphorylation of phosphor-Ser within an acidic context $[39,40]$.

The 5-PCP-InsP $\mathrm{P}_{7}$ affinity resin has also been used to screen for binding partners in cell extracts of the parasite, Trypanosoma cruzi [41]. As is the case for yeast extracts (see above), proteins involved in ribosome biogenesis and nucleotide turnover were both over-represented in the list of captured proteins. One of the novel targets, an uncharacterized protein, which is a putative phosphoribosyl pyrophosphate synthase, was found to contain a candidate SPX domain, which was recently shown to be a widespread PP-InsP binding module [42]. A novel pyrophosphorylation target was also identified and validated: a hypothetical choline/carnitine $o$-acetyltransferasedomain containing protein. Further work is needed to illuminate the biological significance of $5-\mathrm{Ins}_{7}$ interactions with these proteins.

Fiedler and colleagues found that only 22 of the 5 -PCP-InsP $\mathrm{P}_{7}$ binding proteins in their yeast cell extracts (approximately $20 \%$ of the total) were not enriched in parallel screens performed with bead-immobilized $\operatorname{InsP}_{6}[1,38]$. In discussing this observation, the authors asked how the other $80 \%$ of their 'hits' could perform as a specific regulatory molecule for $5-\mathrm{Ins}_{7}$ in vivo, given that this $\mathrm{PP}$-InsP has a total cellular concentration that is only $2-5 \%$ that of $\mathrm{InsP}_{6}$. This is a conundrum that permeates the field; other studies have also described binding proteins that show similar affinities towards PP-InsPs and $\mathrm{InsP}_{6}$ (e.g., [42]). Perhaps in part, the answer is provided by several separate lines of evidence-albeit indirect in nature (summarized in ref [2]) — that indicate much of the cell's complement of InsP $_{6}$ is not free in the cytoplasm but instead may be accumulated into a number of cellular compartments, in which it cannot compete for PP-InsP binding sites.

In addition, Fiedler's group speculated that there was another factor that contributed to their identification of only a small number of binding proteins with specificity for 5-PCP-InsP $\mathrm{P}_{7}$ over 
InsP $_{6}$ : if a protein requires a 2-phosphate monoester for efficient binding, then its selectivity may be compromised by linker attachment at that position. This consideration prompted the group to subsequently synthesize triplexed affinity reagents - a mixture of linker attachments at either the 1-, 2or 3-positions [43]. By using these more advanced reagents to screen lysates from HEK293 and HCT116 cells, the laboratory identified a 3 -fold higher number of proteins exhibiting specificity for 5 -PCP-Ins $\mathrm{P}_{7}$ over Ins: $\mathrm{P}_{6}$, compared to their earlier study with yeast lysates. Among new potential PP-InsP binding proteins that should prove interesting to pursue are the kinase LKB1, which phosphorylates and regulates AMPK, and several enzymes that participate in purine metabolism; these are interesting targets in the context that PP-InsPs act as metabolic regulators.

\section{Delivery of PP-InsPs and PP-InsP Analogues into Live Cells Using Nanocarriers}

The ability to deliver an intracellular signal into cells can directly facilitate studies into its biological actions. However, the anionic nature of polyphosphates prohibits them from crossing the plasma membrane [44]. There are workarounds to this barrier, but several are unsatisfactory because they are physically or biochemically damaging, such as microinjection, electroporation, or chemical transfection (in any case, Lipofectamine 2000 does not efficiently transfer PP-InsPs into cells [45]). To circumvent these restrictions, the negative charges can be 'hidden' by incorporating the polyphosphates into biocompatible nanoparticles that can be accumulated into cells by endocytosis. For example, liposomes have been used to deliver a number of polar molecules into cells: microRNAs [46], siRNA [47], antisense DNA [48], and ATP $[17,49]$. We have recently adapted this technique in order to transfer PP-InsPs into cells; the cargo was spontaneously released during a $3-4 \mathrm{~h}$ loading protocol [50,51]. The mechanism of intracellular release appears to involve the fusion of the endocytosed liposomes with the endosomal and/or lysosomal membranes, causing the cargo to be ejected into the cytoplasm [52].

For example, these methods supported the discovery that 1,5-InsP $\mathrm{P}_{8}$ regulates a cellular pathway for Pi efflux that is dependent upon Xenotropic and Polytropic Retrovirus Receptor 1 (XPR1). It was experiments with PPIP5 $\mathrm{K}^{--}$cells that initially led us to this idea that the Pi efflux pathway is licensed by $1,5-\mathrm{InsP}_{8}$ [50]. To interrogate this genetically-based conclusion with an independent approach, we set out to complement the phenotype using our liposome delivery method. We delivered metabolically-stable 1,5-PCP-Ins $\mathrm{P}_{8}$ into cells, and this rescued Pi efflux in a dose-dependent manner; delivery of either 1-PCP-InsP $\mathrm{P}_{7}$ or 5-PCP-InsP $\mathrm{P}_{7}$ was ineffective [50].

The relatively slow ( $3-4 \mathrm{~h}$ ) liposomal delivery protocol described above has the disadvantage that it is not so useful for the delivery of the natural PP-InsPs; due to their rapid metabolism, it is hard to distinguish the functions of the original cargo from those of its metabolites. To ameliorate this restriction, we recently described the loading into populations of cultured cells of thermosensitive liposomes that only become permeable when the temperature exceeds $37^{\circ} \mathrm{C}$ [53]. These liposomes are also doped with a photothermal, near infra-red carbocyanine dye, and can be induced to 'melt' and release their cargo within $5 \mathrm{~min}$ of illumination of the cultures by a high-power, near infra-red light-emitting diode. We used this methodology to deliver either $1,5-\operatorname{Ins} \mathrm{P}_{8}$ or $1,5-\mathrm{PCP}-\mathrm{Ins} \mathrm{P}_{8}$ into HCT116 cells; both enhanced the rate of cellular Pi uptake to the same extent [53]. These quantitatively equivalent effects of 1,5-InsP $\mathrm{I}_{8}$ and 1,5-PCP-InsP $\mathrm{P}_{8}$ in a cell-based bioassay testify to the value of the PCP analog as a functional bioisostere when studying rapid signaling events that do not involve protein pyrophosphorylation.

In a more recent study, we pursued the discovery that DIPP1 not only hydrolyzes PP-InsPs such as 5 -Ins $\mathrm{P}_{7}$, but also cleaves the $5^{\prime}$-end 7-methylguanosine cap of a specific subset of mRNAs, under the guise of its NUDT3 pseudonym [54]. Decapping exposes the mRNA $5^{\prime}$-end to exonuclease-mediated degradation; this decay pathway plays critical roles in early animal development, cell growth and proliferation, immune response, and mRNA quality control [55]. We posited that 5 -InsP $\mathrm{P}_{7}$ might competitively inhibit mRNA decapping, and thereby stabilize the DIPP1-sensitive transcripts. This proposal was confirmed by liposome-mediated delivery of 5-PCP-InsP $\mathrm{P}_{7}$ into HCT116 cells; this procedure elevated the levels of several DIPP1 mRNA substrates [51]. 
In this context, it is notable that 5 -InsP $\mathrm{P}_{7}$ levels fluctuate in response to the bioenergetic status of the cell (i.e., ATP levels) [56]; this homeostatic process underlies the role of 5-InsP $\mathrm{P}_{7}$ in mediating nutrient-stimulation of insulin secretion from pancreatic $\beta$-cells [56]. These observations rationalize 5-InsP $\mathrm{P}_{7}$ as being a rheostatic signaling molecule that protects bioenergetic health in the face of environmental challenges $[1,6]$. Thus, our delivery of PCP-Ins $\mathrm{P}_{7}$ into cells using liposomes has unveiled an epitranscriptomic control process; we have shown how 5-InsP $\mathrm{P}_{7}$ acts in a molecular pathway by which mRNA structure and stability can be modified in response to fluctuations in the extracellular environment.

Inhibition of $5^{\prime}$-decapping is associated with P-body accumulation [57,58]; the latter are highly dynamic, membrane-less biomolecular condensates that sequester certain mRNAs [59]. While the original concept that P-bodies regulate mRNA decay continues to be pursued [58,60], these organelles are now recognized as important sites for sequestration and storage of mRNAs away from the translating pool [61]. We have shown that liposome delivery of 5-PCP-InsP $\mathrm{P}_{7}$ into cells elicits a $>3$-fold increase in the numbers of P-bodies per cell [51]. We are currently investigating if this effect on P-body dynamics is either a secondary consequence of the elevated levels of stabilized transcripts or a separate function for 5 -InsP $\mathrm{P}_{7}$ (e.g., perhaps through electrostatic interactions with mRNA, just as polyvalent interactions between arginine and RNA assist the phase separation process [62]). As for the ultimate fate of P-body enriched mRNAs, it has been proposed that these transcripts can be rapidly reintroduced into the translating pool, for example, in response to certain environmental cues $[58,63,64]$.

Alternative nanocarriers for PP-InsPs have been described, such as guanidinium-rich oligocarbonate transporters, which, like the liposomes described above, enter cells by the endocytic pathway and spontaneously release their cargo within approximately $4 \mathrm{~h}$ [45]. The latter study by Jessen and colleagues is also significant because it described the first synthesis and application of a 'caged' PP-InsP (Figure 4A and see Section 10 for further discussion).

A

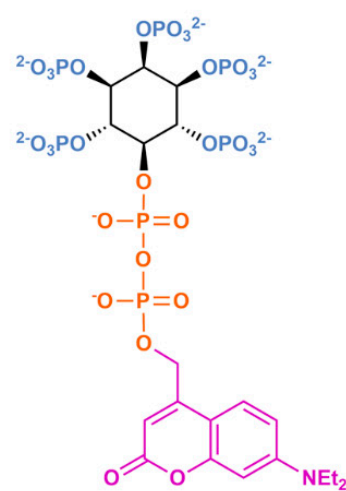

Caged 5-InsP 7
B

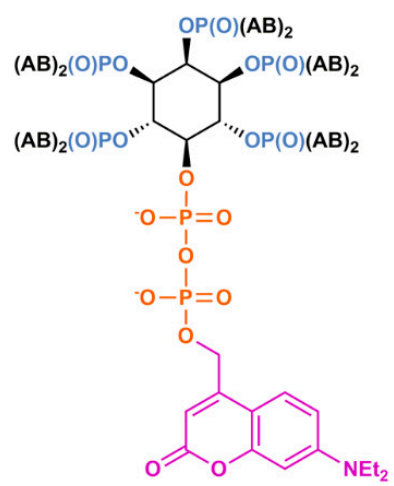

Caged 5-InsP 7

prometabolite<smiles>CC(=O)Oc1ccc(CO)cc1</smiles>

Acetoxybenzyl

(AB)

Figure 4. The structure of a (A) caged 5-InsP 7 and (B) its 'prometabolite'.

\section{Caged and Cell-Permeant PP-InsPs}

Jessen and colleagues produced caged $5-\mathrm{InsP}_{7}$ by adding [7-(diethylamino)coumarin-4-yl]methyl (DEACM) to the 5- $\beta$-phosphate (Figure 4A). The molecule was delivered into cells using guanidinium-rich oligocarbonate transporters [45]. This method offers a dramatic improvement to the temporal and spatial resolution of PP-InsP signaling. Uncaging was accomplished by cell exposure to a 30-s pulse from a $375 \mathrm{~nm}$ UV laser-the first example of controlled 5-InsP $\mathrm{P}_{7}$ augmentation inside a living cell. Thus, it was possible to interrogate the hypothesis $[65,66]$ that 5 -Ins $\mathrm{P}_{7}$ inhibits growth-factor mediated stimulation of AKT partly by competing with its $\mathrm{PH}$ domain $\left(\mathrm{AKT}^{\mathrm{PH}}\right)$ binding site for the signaling phospholipid, $\operatorname{PtdIns}(3,4,5) \mathrm{P}_{3}$, which normally drives AKT translocation from the 
cytoplasm to plasma membrane, where it encounters upstream activating protein kinases. In their experiments, Jessen and colleagues uncaged 5- $\mathrm{InsP}_{7}$ after their $\mathrm{AKT}^{\mathrm{PH}}$ construct had already been relocated to the plasma membrane by prior addition of growth factors [45]. A release of $\mathrm{AKT}^{\mathrm{PH}}$ was observed after $5 \mathrm{~min}$, and nearly completed by $15 \mathrm{~min}$. The length of this time frame could indicate that it depends upon 5 - $\mathrm{InsP}_{7}$ metabolism to $1,5-\mathrm{InsP}_{8}$, but that seems unlikely because the latter is a significantly weaker $\mathrm{AKT}^{\mathrm{PH}}$ ligand [67]. Perhaps instead there are physical constraints that slow down access of $5-\mathrm{InsP}_{7}$ to $\mathrm{AKT}^{\mathrm{PH}}$ that is already associated with $\operatorname{PtdIns}(3,4,5) \mathrm{P}_{3}$. Indeed, even in vitro, 5 -InsP $\mathrm{P}_{7}$ is less potent at competing for the $\mathrm{AKT}^{\mathrm{PH}}-$ bound $\mathrm{Ptd} \operatorname{Ins}(3,4,5) \mathrm{P}_{3}$ if the lipid is prebound to the protein [66].

Another approach to delivering PP-InsPs into cells is to use analogues that are inherently cell-permeant. This can be accomplished by masking the negative charges with lipophilic groups that are naturally removed once the compound has entered the cell; the application of this method to an inositol phosphate (InsP) was first described in 1994 [68]. Acetoxymethyl esters were deployed to mask the phosphate groups, while butyrate was added to the hydroxyls. The resultant, uncharged molecule can penetrate the plasma membrane, and once it is inside cells, intracellular esterases cleave the masking groups and yielded the native inositol phosphate. This technique has been adapted by Jessen and colleagues [69], such that caged 5-InsP $\mathrm{P}_{7}$ was made cell-permeable by attaching acetoxybenzyl groups to the monophosphates and DEACM was added to the 5 - $\beta$-phosphate (Figure 4B). Cell loading and removal of the acetoxybenzyl moieties was completed within $4 \mathrm{hr}$. Subsequently, UV-mediated uncaging of 5 -Ins $\mathrm{P}_{7}$ was found to block $\mathrm{Ca}^{2+}$ oscillations in the mouse pancreatic insulinoma (MIN6) cell-line, after a delay of $15 \mathrm{~min}$ [70]. In a subsequent study using caged 1,5-Ins $\mathrm{P}_{8}$, its photorelease instantly stopped $\mathrm{Ca}^{2+}$ oscillations [71]. Thus, in the earlier study, it seems likely that the delay was due to $5-\mathrm{InsP}_{7}$ phosphorylation to $1,5-\mathrm{InsP}_{8}$. It can be anticipated that inhibition of $\mathrm{Ca}^{2+}$ signaling in $\beta$-cells by 1,5 -InsP $\mathrm{P}_{8}$ would inhibit exocytic insulin secretion [72], but this remains to be demonstrated.

On the other hand, Jessen and colleagues also described an apparently separate effect of 1,5-InsP $\mathrm{P}_{8}$, which, theoretically at least, could promote exocytosis, through PP-InsP's interaction with synaptotagmin-like protein 4 (Slp-4)/granuphilin [71]. The latter is required for insulin granules to dock to the plasma membrane, but such vesicles are not fusion-competent until granuphilin is subsequently detached [73]. A mechanism for granuphilin release has previously been proposed: competition from cytosolic InsP $\mathrm{P}_{6}$ for plasma-membrane associated PtdIns $(4,5 \mathrm{P})_{2}$ binding to granuphilin's $\mathrm{C} 2 \mathrm{~A}$ and $\mathrm{C} 2 \mathrm{~B}$ binding domains [74]. However, 1,5- $\mathrm{InsP}_{8}$ was shown in Jessen's study to also bind to each of these two domains in vitro $\left(\mathrm{K}_{\mathrm{d}}=0.6\right.$ and $5 \mu \mathrm{M}$, respectively [71], as compared to 1.8 and $21 \mu \mathrm{M}$ for InsP 6 [74]). Moreover, the caged 1,5-InsP 8 proved useful in validating PP-InsP's interaction with granuphilin in intact cells; a transfected and membrane-associated eGFP-tagged C2AB domain from granuphilin was found to redistribute into the cytoplasm following uncaging of the $1,5-\mathrm{InsP}_{8}$ [71]. That is, $1,5-\mathrm{Ins} \mathrm{P}_{8}$ was shown to be functionally active even in the presence of steady-state levels of InsP $\mathrm{P}_{6}$. Nevertheless, further work is required to determine how the cell might coordinate the seemingly opposing effects upon insulin secretion that could arise from $1,5-\mathrm{InsP}_{8}$ inhibiting $\mathrm{Ca}^{2+}$ signaling while also causing granuphilin relocalization.

\section{FAM-5-InsP $P_{7}$}

Recently, Jessen's group synthesized a fluorescein-tagged analog of 5-InsP $\left(\right.$ FAM-5-InsP $\left.\mathrm{P}_{7}\right)[51,53]$. This, in itself, is notable for being the first description of the application of click chemistry to the synthesis of a PP-InsP analog, and the synthetic pathways that were involved [53] illuminate a gateway to the preparation of other novel molecules to facilitate further PP-InsP research. The value of this particular molecule is enhanced by the placement of the fluorescent tag onto the 5- $\beta$-phosphate, thereby imparting metabolic stability upon the normally labile diester phosphate [51].

We have used this new analog to validate our liposome delivery protocols $[51,53]$ by exploiting the phenomenon of self-quenching that occurs when a fluorescent probe is present at high concentrations inside vesicles $[75,76]$. Thus, the gain of signal due to unquenching was used to follow the intracellular 
release of the FAM-5-InsP $\mathrm{P}_{7}$ from the vesicles, predominantly into the cytoplasm, by using the tools of confocal microscopy and flow cytometry $[51,53]$.

\section{Conclusions}

Based on the successes described above, we can confidently predict that further, dramatic developments in our understanding of PP-InsP biology will result as additional synthetic analogs provide information from inside intact cells and eventually in vivo. Two developments in particular appear close to fruition. First, photocage technology has improved to the point that the toxic effects of UV-mediated uncaging can be avoided by using photosensitive moieties that respond to visible light while retaining good water solubility [77]. Second, it has been proposed that one oxygen atom of the $\beta$-phosphoryl group of a PP-InsP can be replaced with a sulfur atom, so as to create an analog that can transfer a thiophosphoryl group to protein substrates for pyrophosphorylation [78]. Once transferred, the thiophosphate group can be derivatized and identified by appropriate antibodies. An $\mathrm{InsP}_{7}-\beta \mathrm{S}$ reagent could be delivered into cells using the nanoparticle delivery systems described above. These and other technical innovations will increase the opportunities available to those working in this unique field of signal transduction.

Funding: This research was funded by the Intramural Program of the National Institute of Environmental Health Sciences/NIH, grant number 1Z01ES080046. The APC was funded by the Intramural Program of the National Institute of Environmental Health Sciences/NIH.

Acknowledgments: Work in the authors' laboratory was supported by the Intramural Research Program of the $\mathrm{NIH} /$ National Institute of Environmental Health Sciences.

Conflicts of Interest: The authors declare no conflict of interest. The funders had no role in the design of the study; in the collection, analyses, or interpretation of data; in the writing of the manuscript, or in the decision to publish the results.

\section{Appendix A}

A Note Concerning Inositol Pyrophosphate (PP-InsP) Nomenclature: The literature in this field has a divergent usage of abbreviations to denote individual inositol pyrophosphates and their analogues, accompanied by dueling opinions as to which system is the more accessible to a multidisciplinary audience; one approach to nomenclature is systematic in nature, whereas the other is more colloquial. The latter is the option taken in the text of the current study. Nevertheless, each of the corresponding systematic abbreviations are given here in parentheses, along with full definitions: 1-InsP $\mathrm{P}_{7}$ (1-PP-InsP $\left.\mathrm{P}_{5}\right)=$ 1-diphospho-myo-inositol 2,3,4,5,6-pentakisphosphate; 5-InsP $\mathrm{P}_{7}$ (5-PP-InsP $\left.\mathrm{P}_{5}\right) \quad$ 5-diphospho-myo-inositol 1,2,3,4,6-pentakisphosphate; 1,5-InsP 8 $\left(1,5-[\mathrm{PP}]_{2}-\mathrm{InsP}_{4}\right)=$ 1,5-bis-diphosphoinositol 2,3,4,6-tetrakisphosphate; 5-PP-InsP 4 (also 5-PP-InsP $\left.\mathrm{P}_{4}\right)=$ 5-diphospho-myo-inositol 1,3,4,6-pentakisphosphate; 1-PCP-InsP $\mathrm{P}_{7}$ (1-PCP-InsP $\mathrm{P}_{5}$ ) $=$ myo-inositol 1-methylenediphosphonate-2,3,4,5,6-pentakisphosphate; 5-PCP-InsP $\mathrm{P}_{7}\left(5-\mathrm{PCP}-\mathrm{InsP}_{5}\right)=$ myo-inositol 5-methylenediphosphonate-1,2,3,4,6-pentakisphosphate; 1,5-PCP-InsP $\mathrm{P}_{8}\left(1,5-\mathrm{PCP}-\mathrm{InsP}_{4}\right)=$ myo-inositol 1,5-bis(methylenediphosphonate)-2,3,4,6-tetrakisphosphate; 1-PA-InsP $\mathrm{P}_{7}\left(1-\mathrm{PA}-\mathrm{InsP}_{5}\right)=$ myo-inositol 2,3,4,5,6-pentakisphosphate-1-phosphonoacetate; 5-PA-InsP 7 (5-PA-InsP $\left.\mathrm{P}_{5}\right)=$ myo-inositol 1,2,3,4,6-pentakisphosphate-5-phosphonoacetate; 1,5-PA-InsP $\mathrm{I}_{7}$ (1,5-PA-InsP $\left.\mathrm{P}_{5}\right)=$ myo-inositol 2,3,4,6-tetrakisphosphate-1,5-bis(phosphonoacetate).

\section{References}

1. Shears, S.B. Intimate Connections: Inositol Pyrophosphates at the Interface of Metabolic Regulation and Cell-Signaling. J. Cell Physiol. 2018, 233, 1897-1912. [CrossRef]

2. Randall, T.A.; Gu, C.; Li, X.; Wang, H.; Shears, S.B. A two-way switch for inositol pyrophosphate signaling: Evolutionary history and biological significance of a unique, bifunctional kinase/phosphatase. Adv. Biol. Regul. 2020, 75, 100674. [CrossRef] [PubMed] 
3. Dollins, D.E.; Bai, W.; Fridy, P.C.; Otto, J.C.; Neubauer, J.L.; Gattis, S.G.; Mehta, K.P.M.; York, J.D. Vip1 is a kinase and pyrophosphatase switch that regulates inositol diphosphate signaling. Proc. Natl. Acad. Sci. USA 2020, 117, 9356-9364. [CrossRef] [PubMed]

4. Mulugu, S.; Bai, W.; Fridy, P.C.; Bastidas, R.J.; Otto, J.C.; Dollins, D.E.; Haystead, T.A.; Ribeiro, A.A.; York, J.D. A conserved family of enzymes that phosphorylate inositol hexakisphosphate. Science 2007, 316, 106-109. [CrossRef] [PubMed]

5. Hand, C.E.; Honek, J.F. Phosphate transfer from inositol pyrophosphates InsP5PP and InsP4(PP)2: A semi-empirical investigation. Bioorg. Med. Chem. Lett. 2007, 17, 183-188. [CrossRef] [PubMed]

6. Chakraborty, A. The inositol pyrophosphate pathway in health and diseases. Biol. Rev. Camb. Philos. Soc. 2018, 93, 1203-1227. [CrossRef] [PubMed]

7. Williams, S.P.; Gillaspy, G.E.; Perera, I.Y. Biosynthesis and possible functions of inositol pyrophosphates in plants. Front. Plant. Sci. 2015, 6, 67. [CrossRef] [PubMed]

8. Lee, S.; Kim, M.G.; Ahn, H.; Kim, S. Inositol Pyrophosphates: Signaling Molecules with Pleiotropic Actions in Mammals. Molecules 2020, 25, 2208. [CrossRef]

9. Gomes, A.P.; Blenis, J. A nexus for cellular homeostasis: The interplay between metabolic and signal transduction pathways. Curr. Opin. Biotechnol. 2015, 34, 110-117. [CrossRef]

10. Laha, D.; Parvin, N.; Hofer, A.; Giehl, R.F.H.; Fernandez-Rebollo, N.; von Wiren, N.; Saiardi, A.; Jessen, H.J.; Schaaf, G. Arabidopsis ITPK1 and ITPK2 Have an Evolutionarily Conserved Phytic Acid Kinase Activity. ACS Chem. Biol. 2019, 14, 2127-2133. [CrossRef]

11. Whitfield, H.; White, G.; Sprigg, C.; Riley, A.M.; Potter, B.V.L.; Hemmings, A.M.; Brearley, C.A. An ATP-responsive metabolic cassette comprised of inositol tris/tetrakisphosphate kinase 1 (ITPK1) and inositol pentakisphosphate 2-kinase (IPK1) buffers diphosphosphoinositol phosphate levels. Biochem. J. 2020, 477, 2621-2638. [CrossRef] [PubMed]

12. Adepoju, O.; Williams, S.P.; Craige, B.; Cridland, C.A.; Sharpe, A.K.; Brown, A.M.; Land, E.; Perera, I.Y.; Mena, D.; Sobrado, P.; et al. Inositol Trisphosphate Kinase and Diphosphoinositol Pentakisphosphate Kinase Enzymes Constitute the Inositol Pyrophosphate Synthesis Pathway in Plants. BioRxiv 2019, 724914. [CrossRef]

13. Yang, X.; Shears, S.B. Multitasking in Signal Transduction by a Promiscuous Human Ins $(3,4,5,6) \mathrm{P} 4$ 1-Kinase/Ins(1,3,4)P3 5/6-Kinase. Biochem. J. 2000, 351, 551-555. [CrossRef] [PubMed]

14. Kilari, R.S.; Weaver, J.D.; Shears, S.B.; Safrany, S.T. Understanding inositol pyrophosphate metabolism and function: Kinetic characterization of the DIPPs. FEBS Lett. 2013, 587, 3464-3470. [CrossRef] [PubMed]

15. Steidle, E.A.; Chong, L.S.; Wu, M.; Crooke, E.; Fiedler, D.; Resnick, A.C.; Rolfes, R.J. A novel inositol pyrophosphate phosphatase in Saccharomyces cerevisiae: Siw14 selectively cleaves the beta-phosphate from 5-diphosphoinositol pentakisphosphate (5PP-IP5). J. Biol. Chem. 2016, 291, 6772-6783. [CrossRef]

16. Wang, H.; Gu, C.; Rolfes, R.J.; Jessen, H.J.; Shears, S.B. Structural and biochemical characterization of Siw14: A protein-tyrosine phosphatase fold that metabolizes inositol pyrophosphates. J. Biol. Chem. 2018, 293, 6905-6914. [CrossRef]

17. Gu, C.; Nguyen, H.N.; Ganini, D.; Chen, Z.; Jessen, H.J.; Gu, Z.; Wang, H.; Shears, S.B. KO of 5-InsP7 kinase activity transforms the HCT116 colon cancer cell line into a hypermetabolic, growth-inhibited phenotype. Proc. Natl. Acad. Sci. USA 2017, 114, 11968-11973. [CrossRef]

18. Onnebo, S.M.; Saiardi, A. Inositol pyrophosphates modulate hydrogen peroxide signalling. Biochem. J. 2009, 423, 109-118. [CrossRef]

19. Lev, S.; Li, C.; Desmarini, D.; Saiardi, A.; Fewings, N.L.; Schibeci, S.D.; Sharma, R.; Sorrell, T.C.; Djordjevic, J.T. Inositol Pyrophosphate IP7 Is Crucial for Metabolic Adaptation to the Host Environment and Pathogenicity. mBio 2015, 6, e00531-15. [CrossRef]

20. Menniti, F.S.; Miller, R.N.; Putney, J.W., Jr.; Shears, S.B. Turnover of inositol polyphosphate pyrophosphates in pancreatoma cells. J. Biol. Chem. 1993, 268, 3850-3856.

21. Stephens, L.R.; Radenberg, T.; Thiel, U.; Vogel, G.; Khoo, K.-H.; Dell, A.; Jackson, T.R.; Hawkins, P.T.; Mayr, G.W. The detection, purification, structural characterization and metabolism of diphosphoinositol pentakisphosphate(s) and bisdiphosphoinositol tetrakisphosphate(s). J. Biol. Chem. 1993, 268, 4009-4015. [PubMed]

22. Ganguli, S.; Shah, A.; Hamid, A.; Singh, A.; Palakurti, R.; Bhandari, R. A high energy phosphate jump-From pyrophospho-inositol to pyrophospho-serine. Adv. Biol. Reg. 2019, 75, 100662. [CrossRef] [PubMed] 
23. Riley, A.M.; Wang, H.; Weaver, J.D.; Shears, S.B.; Potter, B.V.L. First synthetic analogues of diphosphoinositol polyphosphates: Interaction with PPIP5 kinase. Chem Comm 2012, 48, 11292-11294. [CrossRef] [PubMed]

24. Wu, M.; Dul, B.E.; Trevisan, A.J.; Fiedler, D. Synthesis and characterization of non-hydrolysable diphosphoinositol polyphosphate second messengers. Chem. Sci. 2013, 4, 405-410. [CrossRef] [PubMed]

25. Riley, A.M.; Wang, H.; Shears, S.B.; BV, L.P. Synthetic tools for studying the chemical biology of InsP $\mathrm{P}_{8}$. Chem Comm 2015, 51, 12605-12608. [CrossRef]

26. Wu, M.; Chong, L.S.; Capolicchio, S.; Jessen, H.J.; Resnick, A.C.; Fiedler, D. Elucidating Diphosphoinositol Polyphosphate Function with Nonhydrolyzable Analogues. Angew. Chem. Int. Ed. Engl. 2014, 53, 9508-9511. [CrossRef]

27. Hager, A.; Wu, M.; Wang, H.; Brown, N.W., Jr.; Shears, S.B.; Veiga, N.; Fiedler, D. Cellular Cations Control Conformational Switching of Inositol Pyrophosphate Analogues. Chemistry 2016, 22, 12406-12414. [CrossRef]

28. Elliott, T.S.; Slowey, A.; Ye, Y.; Conway, S.J. The use of phosphate bioisosteres in medicinal chemistry and chemical biology. MedChemComm 2012, 3, 735-751. [CrossRef]

29. Riley, A.M.; Wang, H.; Shears, S.B.; Potter, B.V.L. Synthesis of an alpha-phosphono-alpha,alphadifluoroacetamide analogue of the diphosphoinositol pentakisphosphate 5-InsP7. MedChemComm 2019, 10, 1165-1172. [CrossRef]

30. Wang, H.; Falck, J.R.; Hall, T.M.; Shears, S.B. Structural basis for an inositol pyrophosphate kinase surmounting phosphate crowding. Nat. Chem. Biol. 2012, 8, 111-116. [CrossRef]

31. Wang, H.; Godage, H.Y.; Riley, A.M.; Weaver, J.D.; Shears, S.B.; Potter, B.V.L. Synthetic Inositol Phosphate Analogs Reveal that PPIP5K2 Has a Surface-Mounted Substrate Capture Site that Is a Target for Drug Discovery. Chem. Biol. 2014, 21, 689-699. [CrossRef] [PubMed]

32. An, Y.; Jessen, H.J.; Wang, H.; Shears, S.B.; Kireev, D. Dynamics of Substrate Processing by PPIP5K2, a Versatile Catalytic Machine. Structure 2019, 27. [CrossRef] [PubMed]

33. Wilson, M.S.; Jessen, H.J.; Saiardi, A. The inositol hexakisphosphate kinases IP6K1 and -2 regulate human cellular phosphate homeostasis, including XPR1-mediated phosphate export. J. Biol. Chem. 2019, 294, 11597-11608. [CrossRef] [PubMed]

34. Capolicchio, S.; Wang, H.; Thakor, D.T.; Shears, S.B.; Jessen, H.J. Synthesis of Densely Phosphorylated Bis-1,5-Diphospho-myo-Inositol Tetrakisphosphate and its Enantiomer by Bidirectional P-Anhydride Formation. Angew. Chem. Int. Ed. Engl. 2014, 53, 9508-9511. [CrossRef] [PubMed]

35. Riley, A.M.; Unterlass, J.; Konieczny, V.; Taylor, C.W.; Helleday, T.; Potter, B.V.L. A synthetic diphosphoinositol phosphate analogue of inositol trisphosphate. MedChemComm 2018, 9, 1105-1113. [CrossRef] [PubMed]

36. Pulloor, N.K.; Nair, S.; Kostic, A.D.; Bist, P.; Weaver, J.D.; Tyagi, R.; Uchil, P.D.; York, J.D.; Snyder, S.H.; Garcia-Sastre, A.; et al. Human Genome-Wide RNAi Screen Identifies an Essential Role for Inositol Pyrophosphates in Type-I Interferon Response. PLoS Pathog. 2014, 10, e1003981. [CrossRef]

37. Chanduri, M.; Rai, A.; Malla, A.B.; Wu, M.; Fiedler, D.; Mallik, R.; Bhandari, R. Inositol hexakisphosphate kinase 1 (IP6K1) activity is required for cytoplasmic dynein-driven transport. Biochem. J. 2016, 473, 3031-3047. [CrossRef]

38. Wu, M.; Chong, L.S.; Perlman, D.H.; Resnick, A.C.; Fiedler, D. Inositol polyphosphates intersect with signaling and metabolic networks via two distinct mechanisms. Proc. Nat. Acad. Sci. USA 2016, 113, E6757-E6765. [CrossRef]

39. Bhandari, R.; Saiardi, A.; Ahmadibeni, Y.; Snowman, A.M.; Resnick, A.C.; Kristiansen, T.Z.; Molina, H.; Pandey, A.; Werner, J.K., Jr.; Juluri, K.R.; et al. Protein pyrophosphorylation by inositol pyrophosphates is a posttranslational event. Proc. Natl. Acad. Sci. USA 2007, 104, 15305-15310. [CrossRef]

40. Saiardi, A.; Bhandari, A.; Resnick, R.; Cain, A.; Snowman, A.M.; Snyder, S.H. Inositol Pyrophosphate: Physiologic Phosphorylation of Proteins. Science 2004, 306, 2101-2105. [CrossRef]

41. Mantilla, B.S.; Brown, N.; Fiedler, D.; Docampo, R. Protein Targets of Inositol Pyrophosphate (5-IP7) in the parasite Trypanosoma cruzi. BioRxiv 2020. [CrossRef]

42. Wild, R.; Gerasimaite, R.; Jung, J.Y.; Truffault, V.; Pavlovic, I.; Schmidt, A.; Saiardi, A.; Jessen, H.J.; Poirier, Y.; Hothorn, M.; et al. Control of eukaryotic phosphate homeostasis by inositol polyphosphate sensor domains. Science 2016, 352, 986-990. [CrossRef] [PubMed]

43. Furkert, D.; Hostachy, S.; Nadler-Holly, M.; Fiedler, D. Triplexed Affinity Reagents to Sample the Mammalian Inositol Pyrophosphate Interactome. Cell Chem. Biol. 2020, 27. [CrossRef] [PubMed]

44. Schultz, C. Prodrugs of biologically active phosphate esters. Bioorg. Med. Chem. 2003, 11, 885-898. [CrossRef] 
45. Pavlovic, I.; Thakor, D.T.; Vargas, J.R.; McKinlay, C.J.; Hauke, S.; Anstaett, P.; Camuna, R.C.; Bigler, L.; Gasser, G.; Schultz, C.L.; et al. Cellular delivery and photochemical release of a caged inositol-pyrophosphate induces PH-domain translocation in cellulo. Nat. Commun. 2016, 7, 10622. [CrossRef] [PubMed]

46. Scheideler, M.; Vidakovic, I.; Prassl, R. Lipid nanocarriers for microRNA delivery. Chem. Phys. Lipids 2019, 226, 104837. [CrossRef]

47. Alshehri, A.; Grabowska, A.; Stolnik, S. Pathways of cellular internalisation of liposomes delivered siRNA and effects on siRNA engagement with target mRNA and silencing in cancer cells. Sci. Rep. 2018, 8, 3748. [CrossRef]

48. Chen, W.; Deng, W.; Goldys, E.M. Light-Triggerable Liposomes for Enhanced Endolysosomal Escape and Gene Silencing in PC12 Cells. Mol. Ther. Nucl. Acids 2017, 7, 366-377. [CrossRef]

49. Mo, R.; Jiang, T.; Gu, Z. Enhanced anticancer efficacy by ATP-mediated liposomal drug delivery. Angew. Chem. Int. Ed. Engl. 2014, 53, 5815-5820. [CrossRef]

50. Li, X.; Gu, C.; Hostachy, S.; Sahu, S.; Wittwer, C.J.; Jessen, H.J.; Fiedler, D.; Wang, H.; Shears, S.B. Control of XPR1-dependent cellular phosphate efflux by InsP8 is an exemplar for functionally-exclusive inositol pyrophosphate signaling. Proc. Natl. Acad. Sci. USA 2020, 117, 3568-3574. [CrossRef]

51. Sahu, S.; Wang, Z.; Jiao, X.; Gu, C.; Jork, N.; Wittwer, C.; Li, X.; Hostachy, S.; Fiedler, D.; Wang, H.; et al. InsP7 is a small-molecule regulator of NUDT3-mediated mRNA decapping and processing-body dynamics. Proc. Natl. Acad. Sci. USA 2020, 17, 19245-19253. [CrossRef] [PubMed]

52. Danaei, M.; Dehghankhold, M.; Ataei, S.; Hasanzadeh Davarani, F.; Javanmard, R.; Dokhani, A.; Khorasani, S.; Mozafari, M.R. Impact of Particle Size and Polydispersity Index on the Clinical Applications of Lipidic Nanocarrier Systems. Pharmaceutics 2018, 10, 57. [CrossRef] [PubMed]

53. Wang, Z.; Jork, N.; Bittner, T.; Wang, H.; Jessen, H.J.; Shears, S.B. Rapid stimulation of cellular Pi uptake by the inositol pyrophosphate InsP8 induced by its photothermal release from lipid nanocarriers using a near infra-red light-emitting diode. Chem. Sci. 2020. [CrossRef]

54. Grudzien-Nogalska, E.; Jiao, X.; Song, M.G.; Hart, R.P.; Kiledjian, M. Nudt3 is an mRNA decapping enzyme that modulates cell migration. RNA 2016, 22, 773-781. [CrossRef]

55. Mugridge, J.S.; Coller, J.; Gross, J.D. Structural and molecular mechanisms for the control of eukaryotic 5'-3' mRNA decay. Nat. Struct. Mol. Biol. 2018, 25, 1077-1085. [CrossRef]

56. Rajasekaran, S.S.; Kim, J.; Gaboardi, G.C.; Gromada, J.; Shears, S.B.; Dos Santos, K.T.; Nolasco, E.L.; Ferreira, S.S.; Illies, C.; Kohler, M.; et al. Inositol hexakisphosphate kinase 1 is a metabolic sensor in pancreatic beta-cells. Cell. Signal. 2018, 46, 120-128. [CrossRef]

57. Standart, N.; Weil, D. P-Bodies: Cytosolic Droplets for Coordinated mRNA Storage. Trends Genet. 2018, 34, 612-626. [CrossRef]

58. Aizer, A.; Kalo, A.; Kafri, P.; Shraga, A.; Ben-Yishay, R.; Jacob, A.; Kinor, N.; Shav-Tal, Y. Quantifying mRNA targeting to P-bodies in living human cells reveals their dual role in mRNA decay and storage. J. Cell Sci. 2014, 127, 4443-4456. [CrossRef]

59. van Leeuwen, W.; Rabouille, C. Cellular stress leads to the formation of membraneless stress assemblies in eukaryotic animal cells. Traffic 2019, 20, 623-63810. [CrossRef]

60. Wang, C.; Schmich, F.; Srivatsa, S.; Weidner, J.; Beerenwinkel, N.; Spang, A. Context-dependent deposition and regulation of mRNAs in P-bodies. eLife 2018, 7, e29815. [CrossRef]

61. Cougot, N.; Molza, A.E.; Giudice, E.; Cavalier, A.; Thomas, D.; Gillet, R. Structural organization of the polysomes adjacent to mammalian processing bodies (P-bodies). RNA Biol. 2013, 10, 314-320. [CrossRef] [PubMed]

62. Verdile, V.; De Paola, E.; Paronetto, M.P. Aberrant Phase Transitions: Side Effects and Novel Therapeutic Strategies in Human Disease. Front. Genet. 2019, 10, 173. [CrossRef] [PubMed]

63. Schutz, S.; Noldeke, E.R.; Sprangers, R. A synergistic network of interactions promotes the formation of in vitro processing bodies and protects mRNA against decapping. Nucleic Acids Res. 2017, 45, 6911-6922. [CrossRef] [PubMed]

64. Hubstenberger, A.; Courel, M.; Benard, M.; Souquere, S.; Ernoult-Lange, M.; Chouaib, R.; Yi, Z.; Morlot, J.B.; Munier, A.; Fradet, M.; et al. P-Body Purification Reveals the Condensation of Repressed mRNA Regulons. Mol. Cell 2017, 68. [CrossRef] 
65. Park, W.S.; Heo, W.D.; Whalen, J.H.; O’Rourke, N.A.; Bryan, H.M.; Meyer, T.; Teruel, M.N. Comprehensive identification of PIP3-regulated PH domains from C. elegans to $\mathrm{H}$. sapiens by model prediction and live imaging. Mol. Cell 2008, 30, 381-392. [CrossRef]

66. Chakraborty, A.; Koldobskiy, M.A.; Bello, N.T.; Maxwell, M.; Potter, J.J.; Juluri, K.R.; Maag, D.; Kim, S.; Huang, A.S.; Dailey, M.J.; et al. Inositol pyrophosphates inhibit akt signaling, thereby regulating insulin sensitivity and weight gain. Cell 2010, 143, 897-910. [CrossRef]

67. Gokhale, N.A.; Zaremba, A.; Janoshazi, A.K.; Weaver, J.D.; Shears, S.B. PPIP5K1 modulates ligand competition between diphosphoinositol polyphosphates and $\operatorname{Ptd} \operatorname{Ins}(3,4,5) \mathrm{P}_{3}$ for polyphosphoinositide-binding domains. Biochem. J. 2013, 453, 413-426. [CrossRef]

68. Vajanaphanich, M.; Schultz, C.; Rudolf, M.T.; Wasserman, M.; Enyedi, P.; Craxton, A.; Shears, S.B.; Tsien, R.Y.; Barrett, K.E.; Traynor-Kaplan, A.E. Long-term uncoupling of chloride secretion from intracellular calcium levels by Ins(3,4,5,6) $\mathrm{P}_{4}$. Nature 1994, 371, 711-714. [CrossRef]

69. Hauke, S.; Dutta, A.K.; Eisenbeis, V.B.; Bezold, D.; Bittner, T.; Wittwer, C.; Thakor, D.; Pavlovic, I.; Schultz, C.; Jessen, H.J. Photolysis of cell-permeant caged inositol pyrophosphates controls oscillations of cytosolic calcium in a beta-cell line. Chem. Sci. 2019, 10, 2687-2692. [CrossRef]

70. Hauke, S.; Bittner, T.; Jessen, H.J.; Schultz, C. Photo-releasable derivatives of inositol pyrophosphates. Meth. Enzymol. 2020, 641, 53-73. [CrossRef]

71. Bittner, T.; Wittwer, C.; Hauke, S.; Wohlwend, D.; Mundinger, S.; Dutta, A.K.; Bezold, D.; Dürr, T.; Friedrich, T.; Schultz, C.; et al. Photolysis of Caged Inositol Pyrophosphate InsP8 Directly Modulates Intracellular Ca ${ }^{2+}$ Oscillations and Controls C2AB Domain Localization. Am. Chem. Soc. 2020, 10606-10611. [CrossRef] [PubMed]

72. Idevall-Hagren, O.; Tengholm, A. Metabolic regulation of calcium signaling in beta cells. Semin. Cell Dev. Biol. 2020, 103, 20-30. [CrossRef] [PubMed]

73. Gomi, H.; Mizutani, S.; Kasai, K.; Itohara, S.; Izumi, T. Granuphilin molecularly docks insulin granules to the fusion machinery. J. Cell Biol. 2005, 171, 99-109. [CrossRef] [PubMed]

74. Lyakhova, T.A.; Knight, J.D. The C2 domains of granuphilin are high-affinity sensors for plasma membrane lipids. Chem. Phys. Lipids 2014, 182, 29-37. [CrossRef] [PubMed]

75. Chen, R.F.; Knutson, J.R. Mechanism of fluorescence concentration quenching of carboxyfluorescein in liposomes: Energy transfer to nonfluorescent dimers. Anal. Biochem. 1988, 172, 61-77. [CrossRef]

76. Kristensen, K.; Henriksen, J.R.; Andresen, T.L. Quantification of leakage from large unilamellar lipid vesicles by fluorescence correlation spectroscopy. Biochim Biophys Acta 2014, 1838, 2994-3002. [CrossRef]

77. Bojtár, M.; Németh, K.; Domahidy, F.; Knorr, G.; Verkman, A.; Kállay, M.; Kele, P. Conditionally Activatable Visible-Light Photocages. J. Am. Chem. Soc. 2020, 142, 15164-15171. [CrossRef]

78. Brown, N.W.; Marmelstein, A.M.; Fiedler, D. Chemical tools for interrogating inositol pyrophosphate structure and function. Chem. Soc. Rev. 2016, 45, 6311-6326. [CrossRef]

(C) 2020 by the authors. Licensee MDPI, Basel, Switzerland. This article is an open access article distributed under the terms and conditions of the Creative Commons Attribution (CC BY) license (http://creativecommons.org/licenses/by/4.0/). 